\title{
COMPLIANCE AND ADHERENCE OF PATIENTS WITH DIABETIC MACULAR EDEMA TO INTRAVITREAL ANTI- VASCULAR ENDOTHELIAL GROWTH FACTOR THERAPY IN DAILY PRACTICE
}

\author{
MAXIMILIAN WEISS, $*$ DAWN A. SIM, MD, PHD, $\dagger$ TINA HEROLD, MD,$*$ RICARDA G. SCHUMANN, MD, * \\ RAFFAEL LIEGL, MD,* CHRISTOPH KERN, MD,* THOMAS KREUTZER, MD,* \\ JOHANNES SCHIEFELBEIN,* MIRIAM ROTTMANN, MPH, $\$$ SIEGFRIED PRIGLINGER, MD,* \\ KARSTEN ULRICH KORTUEM, MD, MHBA*†
}

Purpose: We assessed differences in compliance and adherence (lateness of patients, visual acuity, reasons for abstaining) between patients with diabetic macular edema (DME) and patients with age-related macular degeneration (AMD), both under anti-vascular endothelial growth factor therapy.

Methods: We included 136 patients with DME (36\% women, 65 years, 22 visits, 13.9 injections, and 29.9 months of follow-up) and 109 patients with AMD (59\% women, 76 years, 20 visits, 14.7 injections, and 22.3 months of follow-up) (minimum follow-up of 12 months and at least 5 injections). We assessed missed appointments (lateness $>14$ days) and therapy break-offs (lateness $>100$ days). All delayed patients were called and interviewed for abstaining reasons.

Results: Forty-six percent of patients with DME and $22 \%$ of patients with AMD had at least one break-off. Thirty-five percent of patients with DME and $50 \%$ of patients with AMD were always on schedule. In patients with DME, there was significant correlation $(P=0.017)$ between the number of break-offs and change of visual acuity. In 60\% DME and 38\% AMD of break-off cases, visual acuity was worse than the before break-off. The most common reason for abstaining was comorbidities (33\% AMD and 20\% DME).

Conclusion: There are significant differences between patients with AMD and DME regarding compliance and adherence, which also affects outcome. Strategies to tie patients with DME to costly intravitreal therapy need to be developed to improve outcomes and efficacy.

RETINA 38:2293-2300, 2018

$\mathrm{T}_{\mathrm{b}}^{\mathrm{s}}$ he number of patients diagnosed with diabetes has been estimated to be 382 million worldwide in 2013 and is extrapolated to rise to 592 million in 2035. ${ }^{1}$ This trend is likely to continue, particularly

From the *University Eye Hospital Munich, Ludwig-Maximilian University, Munich, Germany; †Moorfields Eye Hospital, London, United Kingdom; and \$Munich Cancer Registry (MCR) of the Munich Tumour Centre (TZM), Institute for Medical Information Processing, Biometry, and Epidemiology (IBE), University Hospital of Munich, Ludwig-Maximilians-Universität (LMU), Munich, Germany.

This study was conducted in Munich's University Eye Hospital and funded by Munich's Ludwig-Maximilian University.

None of the authors has any conflicting interests to disclose.

Reprint requests: Karsten Ulrich Kortüm, MD, MHBA, University Eye Hospital Munich, Mathildenstraße 8, 80333 München, Munich, Germany; e-mail: karsten.kortuem@med.uni-muenchen.de with the recent increase in the numbers of younger patients diagnosed with diabetes. ${ }^{2}$

Although significant improvements have been made in achieving the recommended levels of hemoglobin A1c (HbA1C), blood pressure, and low-density lipoprotein cholesterol individually, only $18.8 \%$ of patients achieve all goals. ${ }^{3}$ Furthermore, single parameters are reached by only a little more than half of the patients, and thus, a long road remains ahead for the optimal control of this disease. This is relevant to the onset and severity of complications that occur during the course of diabetes. These include acute hyperglycemic and hypoglycemic events, microvascular complications (end-stage renal disease, peripheral vascular disease, lower limb amputation, 
and diabetic eye disease), and cardiovascular complications (coronary artery disease, cerebrovascular disease, and congestive heart failure). ${ }^{4}$ According to the National Health and Nutrition Examination Survey, the most common complication is chronic kidney disease affecting $27.8 \%$ of all U.S. patients with diabetes, followed by the "diabetic foot" $(22.9 \%)$ and eye damage $(18.9 \%) .^{5}$

The incidence of diabetic retinopathy (DR) varies significantly depending on the development status of a country. ${ }^{6}$ Globally, most patients show signs of DR after having diabetes for 10 years. ${ }^{7}$ From a patient's perspective, this remains one of the most dreaded and feared complications of the disease. In the United Kingdom, DR is the second most common cause of legal blindness in the group of working-age individuals, and this carries important socioeconomic implications. ${ }^{8}$ However, severe vision loss mostly occurs at a late stage of disease, and a large therapeutic window that often spans many years exists during the course of diabetes. This opportunity for vision preservation has led to the development of national screening programs wherein DR is graded into various disease stages, and patients are referred in a timely manner for treatment. ${ }^{9}$ In more advanced stages of DR, vision loss is caused by neovascularization in proliferative DR, vitreous hemorrhage, and leakage from existing vessels in case of diabetic macula edema (DME), driven by hypoxia, and the consequent production of vascular endothelial growth factor beside others. ${ }^{10}$

Until recently, retinal laser treatment was the most cost-efficient and effective treatment option for DR and DME. ${ }^{11,12}$ It significantly reduced the risk of blindness, with the cost per quality-of-life adjusted year being US $\$ 6,128 .{ }^{13,14}$ In the last 15 years, new treatment options for center-involving DME by using intravitreal anti-vascular endothelial growth factor medication have been shown to be efficient in clinical trials and therefore have become first-line therapy in the developed world. ${ }^{15,16}$ Depending on the drug of choice and local regulatory-approved labels, monthly to bimonthly injections are recommended by the pharmaceutical companies during the first year of treatment. However, real-world data have shown that in clinical practice, fewer injections are administered, leading to poorer results than those in clinical trials. ${ }^{17}$ Several reasons for this have been proposed: the high cost of treatment, lack of capacity in hospital eyes clinics to administer large volumes of injections, and also design of clinical trials such as RIDE or RISE, which are designed to maximize the chance of showing a treatment outcome. ${ }^{15}$ However, the literaturebased evidence for the difference between the number of injections in clinical trials and those in the "realworld" is limited.
A key component to a successful therapy is a patient's compliance. In diabetes care, compliance is a well-known issue, as patients have multiple appointments in various medical specialties and polypharmacy. Current studies have shown that adherence to an oral hypoglycemic agent ranges from $36 \%$ to $93 \% .^{18,19}$

The aim of our study was to examine and compare patients' compliance with intravitreal anti-vascular endothelial growth factor therapy in DME and agerelated macular degeneration (AMD). Furthermore, the reasons for missed appointments have been evaluated by interviewing patients.

\section{Material and Methods}

\section{Patient-Inclusion Criteria}

We included 136 diabetic (average age 65 years, $36 \%$ women) and 109 AMD (average age 76 years, $59 \%$ women) patients (Table 1) with a first appointment between 2011 and 2015. Intravitreally injected drugs were ranibizumab, aflibercept, or bevacizumab. Patients for this retrospective study were identified by using the Smart Eye Database of Munich's University Eye Hospital. ${ }^{20,21}$ It includes the data of more than 330,000 patients from the electronic health record. ${ }^{22}$ Search criteria to identify patients included the international classification of diseases codes version 10 (ICD-10) of AMD (H35.3) and DR attributable to diabetes mellitus type 2 (E11.3X). Furthermore, additional criteria were as follows: at least 5 intravitreal medical injections in the first year of therapy and a follow-up of at least 12 months. All clinical und patients' demographic data were extracted from the data warehouse.

Patients were referred from general practitioners or nonsurgical practices for treatment of DME and neovascular AMD to the University Eye Hospital of Munich. On every outpatient visit, patients received visual acuity (VA) testing, optical coherence tomography scans, and a clinical examination. Both indications (DME and AMD) were handled by the same pool of staff and in the same location. Retreatment of both patient groups after the initial upload phase was performed according to the mutual recommendations of the German Ophthalmological Society, Federal Society of Eye Doctors, and the German Retina Society after a pro re nata scheme. ${ }^{23,24}$ Diabetic macula edema therapy was continued when there was a reduction of central retinal thickness in optical coherence tomography of at least $10 \%$ and improvement in VA of at least one line within the last 3 months. Agerelated macular degeneration therapy was continued 
Table 1. Demographic Data and Punctuality

\begin{tabular}{|c|c|c|c|}
\hline Item & AMD Cohort & DME Cohort & $P$ \\
\hline Sex (\%) & 45 men (41), 64 women (59) & 87 men (64), 49 women (36) & $<0.001^{*}$ \\
\hline Age, years (average/median) & $76 / 77$ & $65 / 65$ & $<0.001^{*}$ \\
\hline $\begin{array}{l}\text { Average/median amount of } \\
\text { intravitreal injections during } \\
\text { follow-up per patient }\end{array}$ & $14.7 / 12$ & $13.9 / 12$ & $>0.05$ \\
\hline $\begin{array}{l}\text { Average/median amount of } \\
\text { intravitreal injections in first year } \\
\text { of follow-up }\end{array}$ & $7 / 7$ & $7 / 6$ & \\
\hline $\begin{array}{l}\text { Average/median amount of } \\
\text { intravitreal injections in second } \\
\text { year of follow-up }\end{array}$ & $6 / 6$ & $5 / 4$ & \\
\hline Amount of visits average/(median) & $22.4 / 20$ & $24.8 / 22$ & $>0.05$ \\
\hline Follow-up time in months & 22.3 & 29.9 & $0.003^{*}$ \\
\hline \multicolumn{4}{|l|}{ Medications } \\
\hline Ranibizumab & $52 \%$ & $62 \%$ & \\
\hline Aflibercept & $44 \%$ & $31 \%$ & \\
\hline \multicolumn{4}{|l|}{ Punctuality } \\
\hline Average/median delay in days & 28.8/24 & $33.4 / 29$ & $0.013^{*}$ \\
\hline Delayed patients in first year & $31 \%$ & $51 \%$ & $0.002^{*}$ \\
\hline Delayed patients in second year & $43 \%$ & $48 \%$ & 0.52 \\
\hline $\begin{array}{l}\text { Average/median delay in days } \\
\text { awaiting approval of the health } \\
\text { insurance company }\end{array}$ & $34.8 / 27$ & $50.2 / 42$ & $0.012^{*}$ \\
\hline At least one therapy break-off & $22 \%$ & $46 \%$ & $<0.001^{*}$ \\
\hline $\begin{array}{l}\text { Patients with at least one therapy } \\
\text { break-off in first year }\end{array}$ & $10 \%$ & $21 \%$ & $0.015^{\star}$ \\
\hline $\begin{array}{l}\text { Patients with at least one therapy } \\
\text { break-off in second year }\end{array}$ & $15 \%$ & $28 \%$ & 0.063 \\
\hline $\begin{array}{l}\text { Never been late by more than } 14 \\
\text { days }\end{array}$ & $50 \%$ & $35 \%$ & $0.017^{\star}$ \\
\hline $\begin{array}{l}\text { In less than } 10 \% \text { of appointments, } \\
\text { more than } 14 \text { days late }\end{array}$ & $90 \%$ & $71 \%$ & $0.001^{*}$ \\
\hline
\end{tabular}

*significant difference.

when at least one of the six criteria was met: persisting or increasing subretinal fluid, macular edema, or cystoid intraretinal spaces, increase of pigment epithelium detachment, new intraretinal or subretinal hemorrhages, or decrease in VA.

At the end of every clinical consultation, the next follow-up appointment was routinely scheduled and noted in the electronic health record. We compared the intended follow-up data with the actual date. Attendance 14 days before or after the intended date was defined as acceptable (Figure 1). A delay of more than 14 days was defined as a missed appointment.
Absence of more than 100 days of therapy was determined as a therapy break-off. If a reason was given for the delay, it was noted in a spreadsheet. If no reason was provided, we phoned the patients with at least one missed appointment or treatment break-off. Table 2 gives an overview of reason categories for missed appointments given by the patients.

Before October 1, 2014, patients had to send an application to their health insurance company, which ultimately decided whether the patient would be reimbursed for the costs of the treatment. Because this administrative process could also affect compliance, we

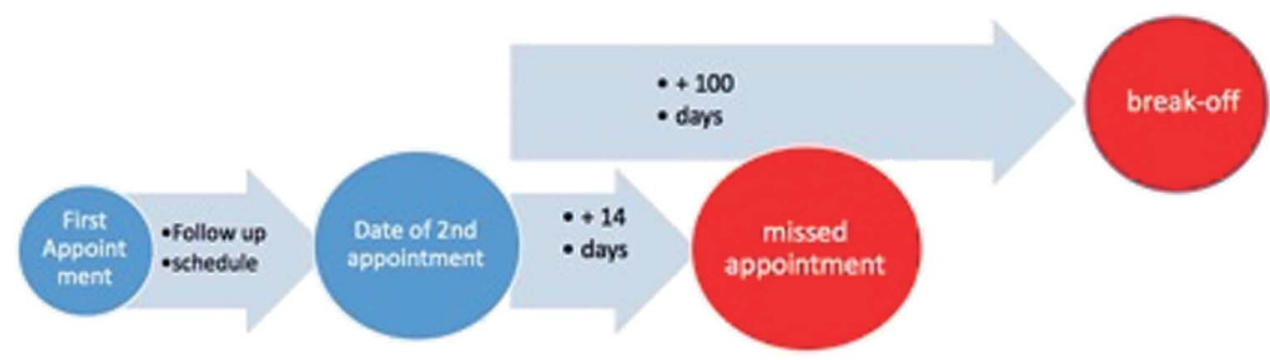

Fig. 1. Illustration of definition of missed appointment and therapy break-off. 
Table 2. Reasons for Abstaining Appointments

\begin{tabular}{lccc}
\hline \multicolumn{1}{c}{ Reason for Absence } & AMD (Absolute n)/(\%) & DME (Absolute n)/(\%) & $P$ \\
\hline Other illness & $13 / 33$ & $21 / 20$ & $0.045^{*}$ \\
No explanation & $3 / 8$ & $18 / 17$ & $13 / 12$ \\
Personal & $5 / 13$ & $11 / 10$ \\
Problems with the clinic & $7 / 18$ & $9 / 8$ \\
Change of doctor & $4 / 10$ & $8 / 8$ \\
Problems with the insurance company & $3 / 8$ & $7 / 7$ \\
Problem of communication & $1 / 3$ & $6 / 6$ \\
No prospect of improvement & $1 / 3$ & $3 / 3$ \\
Patient died & 0 & $3 / 3$ \\
Complication with injection & $1 / 3$ & $3 / 3$ \\
Transportation issue & $1 / 3$ & $2 / 2$ \\
Obvious compliance problems & 0 & $2 / 2$ \\
Family problems & $1 / 3$ & \\
\hline
\end{tabular}

*significant difference.

evaluated the possible effect of any delay caused by insurance companies regarding the two diseases. Delays caused by insurances were noted in the patients' records. This administrative delay was not included in the calculation of other reasons for delays. The numbers of therapy break-offs before and after this due date were analyzed.

Approval for this study was provided by the institutional review board of the University Eye Hospital of Munich and adhered to the tenets of the Declaration of Helsinki.

\section{Statistical Analysis}

The data were downloaded from the database in Excel 2013, which was used in combination with SPSS for statistics. Mann-Whitney $U$ test and chisquare test were used to examine continuous variables and frequency data, respectively. The Kruskal-Wallis test was used to compare differences in VA in relation to the number of therapy break-offs. A $P$ value $<0.05$ was considered statistically significant.

\section{Results}

\section{Population and Compliance}

The AMD and DME patient cohorts had similar numbers of intravitreal injections (14.7 AMD and 13.9 DME) and visits (20 AMD and 22 DME) and a comparable follow-up time (22.3 months AMD and 29.9 months DME). Forty-six percent of patients with DME and 22\% of patients with AMD had at least one therapy break-off. The gap between the scheduled appointment and the actual appointment was 33.4 days for patients with DME and 28.8 days for patients with AMD (Table 1). Thirty-five percent of patients with DME and 50\% of patients with AMD always returned within the intended timeframe (Table 1, punctuality). Both groups had a significantly increasing amount $(P$ $<0.001$ ) of missed appointments with rising numbers of visits during their therapy. No significant difference in sex distribution could be found in both patient groups concerning therapy break-offs, delays, delays due to health insurance issues, number of injections, and number of visits.

\section{Visual Acuity}

We found that, for patients with DME, VA decreased with more treatment break-offs (KruskalWallis test: $P=0.017$ ) (Figure 2). The number of injections did not correlate significantly with the number of break-offs. For patients with AMD, no correlation was found for either parameter (Figure 3). Furthermore, we determined decrease of VA as a consequence of a treatment break-off in $60 \%$ of patients with DME and in $38 \%$ of patients with AMD; however, there was no significant difference between both groups $(P>$ $0.05)$.

Reasons for Missed Appointments and Therapy Break-Offs

Until automatic acceptance and reimbursement of intravitreal medical therapies by the health insurances, patients showed a delay of more than 1 month because of long processing time (Table 1). Before automatic reimbursement by German health insurances, $28 \%$ of patients with AMD and 52\% of patients with DME had at least one therapy break-off. After this due date, $16 \%$ of patients with AMD and $31 \%$ of patients with DME had at least one therapy break-off.

We were able to reach $82 \%$ of AMD patients with one or more therapy break-offs or missed appointments (42 of 52 patients) and $90 \%$ of the patients with 


\section{Change in ETDRS letters by number of therapy break-offs in DME patients}

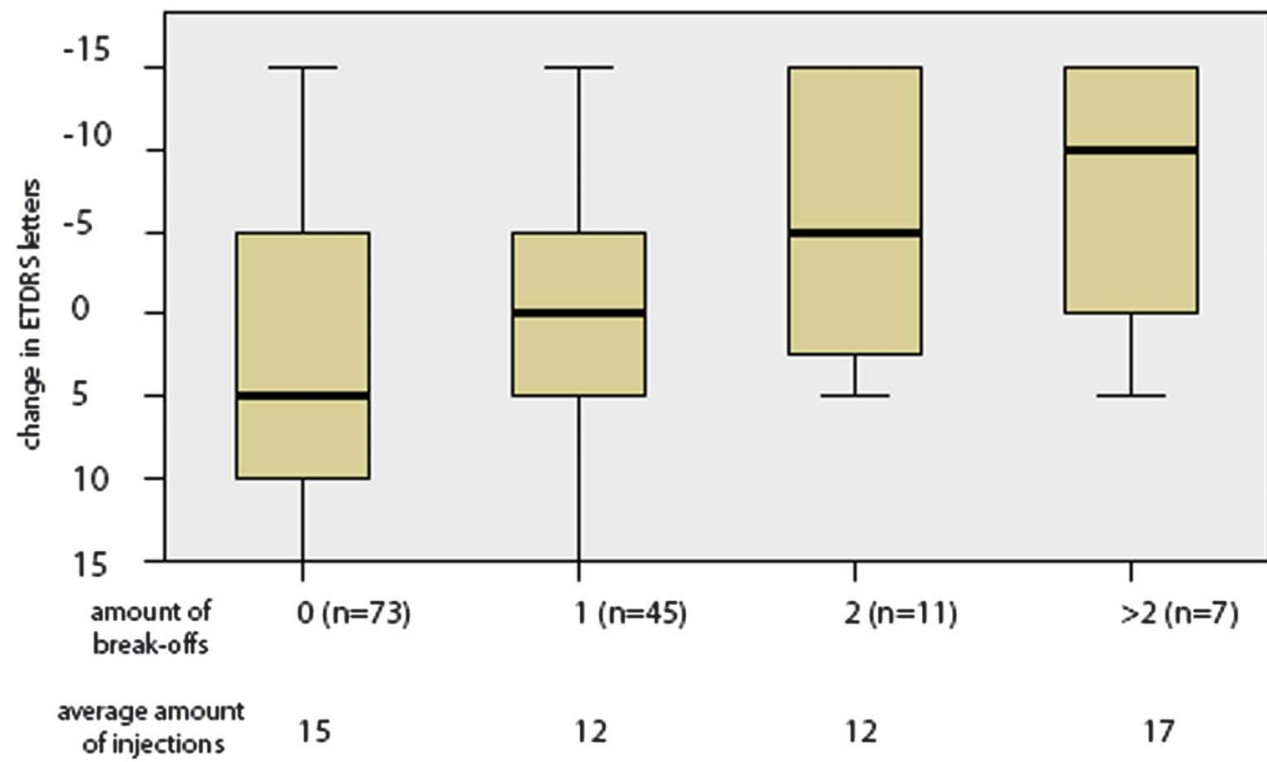

Fig. 2. Change in Early Treatment Diabetic Retinopathy Study letters of patients with diabetic macular edema (y-axis) before and after intravitreal therapy in relation to the amount of break-offs $(0,1$, 2 , or more than 2 ).

DME (85 of 94 patients). As patients could have had several missed appointments, several reasons for abstaining could be given. Overall, other illnesses were the main factor for missed appointments/therapy break-offs for both groups (33\% AMD vs. 20\% DME). The largest difference between the two groups was for "no explanation" (8\% AMD vs. $17 \%$ DME $P=0.045)$.
Both groups had multiple similar reasons, e.g., personal reasons (Table 2).

\section{Discussion}

Adherence and compliance to therapy is a major issue in patients with diabetes. ${ }^{18}$ In our retrospective

\section{Change in ETDRS letters by number of therapy break-offs in}

\section{AMD patients}

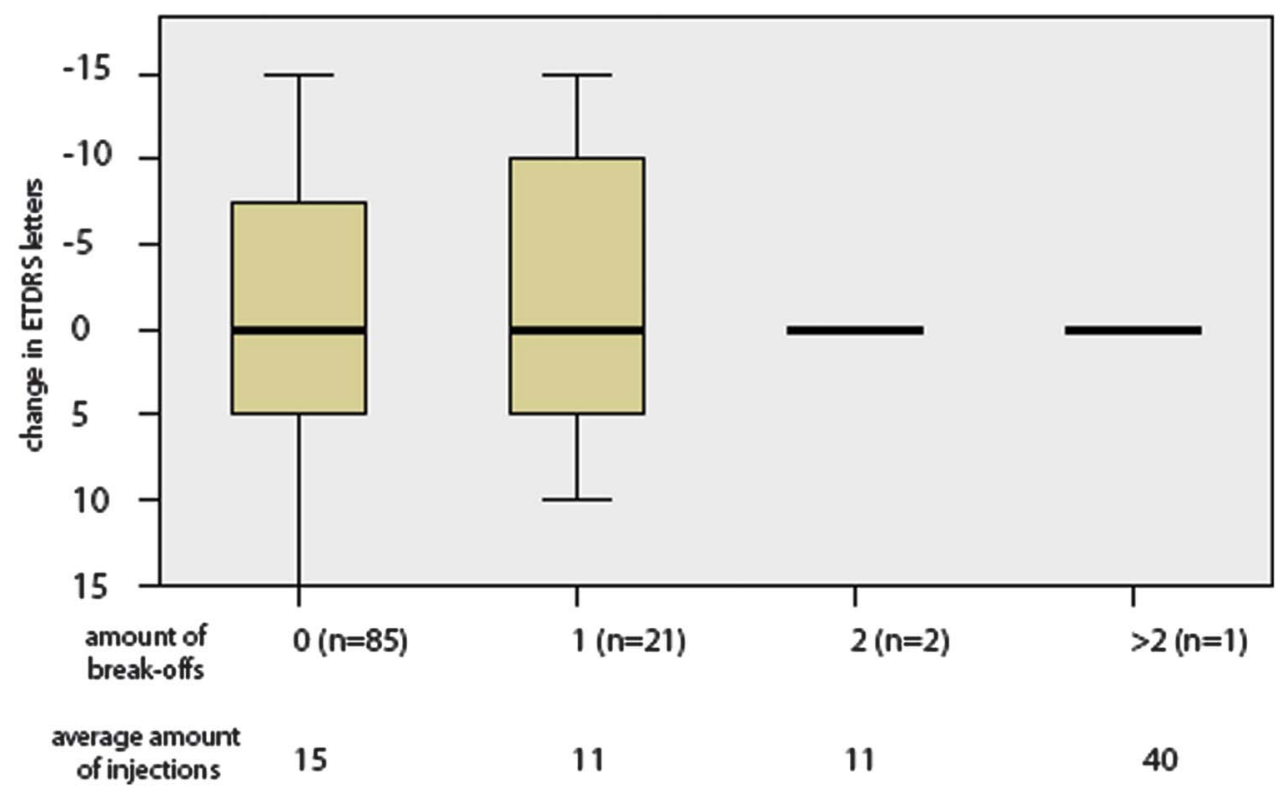

Fig. 3. Change in Early Treatment Diabetic Retinopathy Study letters of patients with age-related macular disease (y-axis) before and after intravitreal therapy in relation to the amount of breakoffs $(0,1,2$, or more than 2$)$. 
analysis of compliance of DME and AMD patients with similar numbers of visits and injections, we found a significant difference in the amount of missed appointments (50\% of AMD had never been late vs. only $35 \%$ of patients with DME), the length of their average delay (28.8 days AMD vs. 33.4 days DME), and the amount of therapy break-off (22\% of AMD patients with at least therapy break-off vs. $46 \%$ patients with DME). An alignment in behavior regarding delays and break-offs between both groups during the second year of treatment could be observed. This might be due to the very incompliant diabetic patients dropped out in the second year of observation. However, diabetic patients are still more often delayed $(43 \%$ patients with AMD vs. $48 \%$ patients with DME) and broke off (15\% in patients with AMD vs. $28 \%$ patients with DME) their therapy than patients with AMD. In our study, there were no differences between sexes, although it is well known, that there are sex-related differences in diseases and also therapeutic compliance. ${ }^{25,26}$ According to our telephone survey, the most frequent reason for abstaining was other illnesses for both groups (33\% AMD and 20\% DME). The only significant difference found between the two groups was for no explanation (8\% AMD and 17\% DME).

The reasons for noncompliance in medicine are multifactorial. Demographic variables, disease factors, psychiatric disorders, and treatment factors such as the duration of the treatment or the frequency of dosing have been studied, but none of them is consistently related to compliance. ${ }^{27}$ But in general, the more severe a contributing factor, the lower is the compliance. One study showed that, other than education and income, older diabetic patients are generally less compliant than younger people. ${ }^{28}$ In our study, however, the younger DME patient group (average age 65 years) was significantly less compliant than the AMD reference group (average age 76 years). Similar results were found in relation to oral diabetic medication. According to a meta-analysis of 38 studies, only $58 \%$ of patients with diabetes had a 12 -month medication possession ratio of more than $80 \% .^{18}$ In our study, a significant $(P<0.001)$ correlation was seen between the number of visits and the number of missed appointments. Long-term compliance is difficult to maintain and leads to compromised health benefits and therefore economic consequences. ${ }^{18}$

Our study stated a negative correlation between the amount of therapy break-offs and a poorer VA outcome in patients with DME; however, this effect could not be seen in patients with AMD. A recent meta-analysis of 63 studies assessing the correlation between adherence to medical treatment and objective outcome measures showed that good and bad therapy adherence can lead to a $26 \%$ difference in outcome and results. ${ }^{29}$ The consequence of improper treatment can be blindness in patients. ${ }^{30}$

As compliance is a multifactorial construct, among other approaches, the training of staff to teach adherence and to support and not to blame patients seems to be beneficial. ${ }^{31}$ Another important factor for compliance is doctor-to-patient communication. ${ }^{32} \mathrm{Six}$ percent of patients with DME and two percent of patients with AMD indicated a lack of communication during their interaction with doctors. A possible solution might be to employ interpreters in hospitals to overcome language barriers. ${ }^{33}$ This might also help to reduce the number of patients indicated as having "no prospect of improvement."

The main factor for therapy break-offs, as recounted during the interviews with both groups, was other illnesses. Based on various studies, nearly every patient with AMD has at least another comorbidity, and more than $80 \%$ have five or more. ${ }^{34}$ Similar results can be seen with DME patients. ${ }^{35}$ One of the main problems is that, after hospitalization, patients forget to resume their eye treatment. Recent data about the impact of intravitreal injection therapy on quality of life of patients with DME and retinal vein occlusions showed that fewer injections are requested by patients. ${ }^{36}$ Reminding patients of the importance of continuous therapy and the monitoring of the patient through appropriate software might reduce the impact of comorbidity. The problem that, with an increasing number of visits, compliance reduction might be addressed by new treatment options such as navigated laser treatment, which involves a reduction of injections and possibly a reduction in outpatient visits. ${ }^{37}$

One study has shown that a significant reduction in missed appointments can be achieved through reminding patients by text message. ${ }^{38}$ Patients with DME had a two-fold tendency to provide no explanation for their therapy break-offs. Up until 2014, patients had to send a therapy application to their health insurance company, which then needed to approve the therapy. This process caused delays for both study groups, and a significant difference was detected in delays. This was also given as a reason for treatment break-off in 8 percent in both groups. After intravitreal therapy was approved automatically by health insurances, the rate of therapy break-offs was reduced. However, the ratio between patients with AMD and DME remained stable. Patients with DME had in both periods the double percentage of therapy break-offs. Patients with AMD have been shown to be willing to undertake burdens to improve their VA outcome, whereas many patients with DME seem to suffer under general poor compliance, have less disease insight, and seem to prefer to avoid this topic. ${ }^{19,39}$ 
The illness of diabetes contributes to a large economic burden for the health care system because of direct costs of $\$ 176$ billion and $\$ 69$ billion in reduced productivity. ${ }^{40}$ The cost for intravitreal treatment is around $1200 \$$ to $1950 \$$ per injection depending on the drug used.$^{41}$ Under optimal conditions, the cost for treatment is $\$ 11$ to 138/quality-of-life adjusted year with bevacizumab. ${ }^{42}$

Our data support the idea, that a prospective study, with questionnaires determining reasons for missed appointments, would be beneficial. Moreover, a randomized trial with one group of patients being reminded of their appointments automatically by calls or using dedicated software and another group assigned to the traditional workflow might provide better insight into this problem. However, incentives probably need to be put into place to achieve this aim.

A possible limitation of this study is that we have no data that shows whether patients with DME and AMD in a German university hospital are representative for an "average" patient. As around 70\% of intravitreal therapy is administered outside public hospitals in private practice environments, but still under public insurance coverage, it is possible that only patients with advanced disease are referred to a public hospital. ${ }^{43}$ Furthermore, VA taking was not on a level for clinical trials. However, for both patient groups, the same location and the same staff pool were used. During the telephone survey, some patients indicated that they don't know why they missed the appointment. This might also be as the appointments in question ranged back by up to two years.

In conclusion, patients with DME seem to have worse therapy compliance with a larger effect on their VA outcome compared with AMD patients. Both groups have similar reasons for missed appointments or treatment break-offs. But the lack of therapy compliance in patients with DME in our study seem to lead to a worse outcome and therefore represents a huge burden for the health insurance system in high therapy costs and the need for restarting after a therapy break-off. Although new therapy approaches that might reduce the burden of injection therapy are in sight, teaching programs for doctors and reminding systems and software that might help patients to stick to such a long-term therapy, could be a cost-efficient method for this problem.

Key words: compliance, diabetic macular edema, adherence, anti-VEGF, intravitreal injection, agerelated macular degeneration, continuity of therapy, database.

\section{References}

1. Guariguata L, Whiting DR, Hambleton I, et al. Global estimates of diabetes prevalence for 2013 and projections for 2035. Diabetes Res Clin Pract 2014;103:137-149.
2. Dabelea D, Mayer-Davis EJ, Saydah S, et al. Prevalence of type 1 and type 2 diabetes among children and adolescents from 2001 to 2009. JAMA 2014;311:1778-1786.

3. Stark Casagrande S, Fradkin JE, Saydah SH, et al. The prevalence of meeting A1C, blood pressure, and LDL goals among people with diabetes, 1988-2010. Diabetes Care 2013;36: 2271-2279.

4. Huang ES, Laiteerapong N, Liu JY, et al. Rates of complications and mortality in older patients with diabetes mellitus: the diabetes and aging study. JAMA Intern Med 2014;174:251-258.

5. Deshpande AD, Harris-Hayes M, Schootman M. Epidemiology of diabetes and diabetes-related complications. Phys Ther 2008;88:1254-1264.

6. Ruta LM, Magliano DJ, LeMesurier R, et al. Prevalence of diabetic retinopathy in type 2 diabetes in developing and developed countries. Diabetic Med 2013;30:387-398.

7. Yau JWY, Rogers SL, Kawasaki R, et al. Global prevalence and major risk factors of diabetic retinopathy. Diabetes Care 2012;35:556-564.

8. Liew G, Michaelides M, Bunce C. A comparison of the causes of blindness certifications in England and Wales in working age adults (16-64 years), 1999-2000 with 2009-2010. BMJ open;2014;4:e004015.

9. Harding S, Greenwood R, Aldington S, et al. Grading and disease management in national screening for diabetic retinopathy in England and Wales. Diabetic Med 2003;20:965-971.

10. Rabinowitz R, Yagev R, Shoham A, et al. Comparison between clinical and ultrasound findings in patients with vitreous hemorrhage. Eye 2004;18:253-256.

11. Lee CM, Olk RJ. Modified grid laser photocoagulation for diffuse diabetic macular edema: long-term visual results. Ophthalmology 1991;98:1594-1602.

12. Doft BH, Blankenship GW. Single versus multiple treatment sessions of argon laser panretinal photocoagulation for proliferative diabetic retinopathy. Ophthalmology 1982;89:772-779.

13. Writing Committee for the Diabetic Retinopathy Clinical Research Network. Panretinal photocoagulation vs intravitreous ranibizumab for proliferative diabetic retinopathy: a randomized clinical trial. JAMA 2015;314:2137-2146.

14. Lin J, Chang JS, Smiddy WE. Cost evaluation of panretinal photocoagulation versus intravitreal ranibizumab for proliferative diabetic retinopathy. Ophthalmology 2016;123: 1912-1918.

15. Nguyen QD, Brown DM, Marcus DM, et al. Ranibizumab for diabetic macular edema: results from 2 phase III randomized trials: RISE and RIDE. Ophthalmology 2012;119:789-801.

16. Korobelnik J-F, Do DV, Schmidt-Erfurth U, et al. Intravitreal aflibercept for diabetic macular edema. Ophthalmology 2014; 121:2247-2254.

17. Egan C, Zhu H, Lee A, et al. The United Kingdom Diabetic Retinopathy Electronic Medical Record Users Group, Report 1: baseline characteristics and visual acuity outcomes in eyes treated with intravitreal injections of ranibizumab for diabetic macular oedema. Br J Ophthalmol 2017;101:75-80.

18. Cramer JA, Benedict Á, Muszbek N, et al. The significance of compliance and persistence in the treatment of diabetes, hypertension and dyslipidaemia: a review. Int J Clin Pract 2008;62: 76-87.

19. Cramer J. A systematic review of adherence, treatment satisfaction and costs, in fixed-dose combination regimens in type 2 diabetes. Curr Med Res Opin 2004;27:1218-1224.

20. Kortum K, Muller M, Hirneiss C, et al. Smart eye data: development of a foundation for medical research using smart data applications [in German]. Ophthalmologe 2016;113:469-477. 
21. Kortüm KU, Müller M, Kern C, et al. Using electronic health records to build an ophthalmological data warehouse and visualize patients' data. Am J Ophthalmol 2017;148:84-93.

22. Kortum KU, Muller M, Babenko A, et al. Development of an ophthalmological clinical information system for inpatient eye clinics [in German]. Ophthalmologe 2015;112:995-1001.

23. Gesellschaft DO. Die Anti-VEGF-Therapie bei der neovaskulären altersabhängigen Makuladegeneration-therapeutische Strategien. Der Ophthalmologe 2015;112:237-245.

24. Ziemssen F, Helbig H, Lemmen K, et al. Stellungnahme der Deutschen Ophthalmologischen Gesellschaft, der Retinologischen Gesellschaft und des Berufsverbandes der Augenärzte Deutschlands: Therapie der diabetischen Makulopathie (Stand April 2013). Klinische Monatsblatter fur Augenheilkunde 2013;230:614-628.

25. Chen SL, Lee WL, Liang T, et al. Factors associated with gender differences in medication adherence: a longitudinal study. J Adv Nurs 2014;70:2031-2040.

26. Crimmins EM, Kim JK, Solé-Auró A. Gender differences in health: results from SHARE, ELSA and HRS. Eur J Public Health $2011 ; 21: 81-91$.

27. Vermeire E, Hearnshaw H, Van Royen P, et al. Patient adherence to treatment: three decades of research. A comprehensive review. J Clin Pharm Ther 2001;26:331-342.

28. Attyia A, El Bahnasy R, Abu Salem M, et al. Compliance of diabetic patients with the prescribed clinical regimen. Menoufia Med J 2013;26:54-57.

29. DiMatteo MR, Giordani PJ, Lepper HS, et al. Patient adherence and medical treatment outcomes: a meta-analysis. Med Care 2002;40:794-811.

30. Chader GJ, Taylor A. Preface: the aging eye: normal changes, age-related diseases, and sight-saving approaches. Invest Ophthalmol Vis Sci 2013;54:2-5.

31. Burkhart PV, Sabate E. Adherence to long-term therapies: evidence for action. J Nurs Scholarsh 2003;35:207.

32. Shukla AK, Yadav VS, Kastury N. Doctor-patient communication: an important but often ignored aspect in clinical medicine. J Indian Acad Clin Med 2010;11:208-211.
33. Karliner LS, Jacobs EA, Chen AH, et al. Do professional interpreters improve clinical care for patients with limited English Proficiency? A systematic review of the literature. Health Serv Res 2007;42:727-754.

34. Shah S, Zlateva G, Zhou S, et al. Comparison of comorbid conditions between wet AMD patients and a control Cohort in the medicare Population. Invest Ophthalmol Vis Sci 2006;47: 2209.

35. Campbell J, Dugel PU, Cole A, et al. Comorbidity and healthcare visit burden in elderly diabetic macular edema patients. Invest Ophthalmol Vis Sci 2015;56:2145.

36. Sivaprasad S, Oyetunde S. Impact of injection therapy on retinal patients with diabetic macular edema or retinal vein occlusion. Clin Ophthalmol 2016;10:939-946.

37. Liegl R, Langer J, Seidensticker F, et al. Comparative evaluation of combined navigated laser photocoagulation and intravitreal ranibizumab in the treatment of diabetic macular edema. PLoS One 2014;9:e113981.

38. Downer SR, Meara JG, Da Costa AC. Use of SMS text messaging to improve outpatient attendance. Med J Aust 2005; 183:366-368.

39. Mueller S, Agostini H, Ehlken C, et al. Patient preferences in the treatment of neovascular age-related macular degeneration: a discrete choice experiment. Ophthalmology 2016;123:876883.

40. Petersen M. Economic costs of diabetes in the U.S. in 2012. Diabetes Care 2016;39:1033-1046.

41. Raftery J, Clegg A, Jones J, et al. Ranibizumab (Lucentis) versus bevacizumab (Avastin): modelling cost effectiveness. Br J Ophthalmol 2007;91:1244-1246.

42. Stein JD, Newman-Casey PA, Kim DD, et al. Cost-effectiveness of various interventions for newly diagnosed diabetic macular edema. Ophthalmology 2013;120:1835-1842.

43. Wenzel M, Auffarth G, Scharrer A, et al. Intraokulare operationen im jahr 2015: ergebnisse der aktuellen umfrage von DGII, DOG, BVA und BDOC. Ophthalmo Chirurgie 2015; 26:193-200. 